$11-1999$

\title{
The Impact of Neighborhoods, Schools, and Malls on the Spatial Distribution of Property Damage
}

Teresa C. Lagrange

Cleveland State University, t.lagrange@csuohio.edu

Follow this and additional works at: https://engagedscholarship.csuohio.edu/clsoc_crim_facpub

Part of the Criminology Commons

How does access to this work benefit you? Let us know!

\section{Original Citation}

Lagrange, T. C. (1999). The Impact of Neighborhoods, Schools, and Malls on the Spatial Distribution of Property Damage. Journal Of Research in Crime and Delinquency, 36(4), 393-422. doi:10.1177/

0022427899036004003

\section{Repository Citation}

Lagrange, Teresa C., "The Impact of Neighborhoods, Schools, and Malls on the Spatial Distribution of Property Damage" (1999). Sociology \& Criminology Faculty Publications. 56.

https://engagedscholarship.csuohio.edu/clsoc_crim_facpub/56

This Article is brought to you for free and open access by the Sociology \& Criminology Department at EngagedScholarship@CSU. It has been accepted for inclusion in Sociology \& Criminology Faculty Publications by an authorized administrator of EngagedScholarship@CSU. For more information, please contact library.es@csuohio.edu. 


\title{
THE IMPACT OF NEIGHBORHOODS, SCHOOLS, AND MALLS ON THE SPATIAL DISTRIBUTION OF PROPERTY DAMAGE
}

\author{
TERESA C. LAGRANGE
}

\begin{abstract}
Using data obtained from three different sources, principles derived from routine activities theory are used to predict the distribution of minor property crimes in a medium-sized Canadian city during a 1-year period. Mischief and vandalism incidents recorded by the local police, transit department, and department of parks and recreation are aggregated by census enumeration area using mapping software, and analyzed in relation to three sets of predictors: (1) neighborhood demographic characteristics; (2) the proximity of shopping malls; and (3) the proximity of public and Catholic senior and junior high schools. Similar patterns observed for the three types of damage are examined in relation to the convergence of potential offenders, reduced guardianship, and increased opportunity as derived from routine activities theory.
\end{abstract}

Analysis of the geographic distribution of crime has had a long history in criminology, dating from the work of sociologists at the Chicago School. Most of this research has focused on index crimes such as homicide, robbery, rape, or burglary, and it has linked rates of offending to the social and residential characteristics of the neighborhoods where these crimes occur. Minor crimes, however, such as property damage and vandalism, occur far more frequently in any city than the more widely studied index offenses. Recent research has suggested that these crimes may be significant factors in the occurrence of urban crime in a more general sense, through processes described as the "broken windows" effect or "spiral of decay" (Felson 1998:131; Skogan 1990:40; see also Kelling and Coles 1996). According to these perspectives, the accumulation of minor property damage sends a subtle signal to potential 
offenders that guardianship is low and that crimes may be carried out undetected. Thus, crimes of all types are more likely to be committed in rundown areas of a city. An understanding of the geographic distribution of minor offenses like property damage and vandalism, therefore, has the potential to shed light on the spatial patterns of a much broader range of criminal activity.

Although the causal variables that are usually examined in relation to spatial variations in crime rates have been those associated with structural theories of offending (Bursik 1988; Park and Burgess 1933; Shaw and McKay 1942; Snodgrass 1976), the broken windows phenomenon emphasizes that the immediate situational context may also be an important factor in the occurrence of crime. A would-be offender needs a suitable victim or target, and must encounter it in circumstances that permit a crime to be carried out without interruption. Recognition of these fundamental observations has led to the recent development of perspectives such as routine activities theory, which looks beyond the attributes of residents of high-crime areas to consider those social and environmental factors that make such areas conducive to crime (Cohen and Felson 1979; Felson 1986, 1987, 1994, 1998; Felson and Cohen 1980). As formulated and developed by Felson and Cohen, routine activities theory portrays crime as the convergence of the following three elements: motivated offenders, potential victims or targets, and unguarded access (Felson 1998:53). Thus, features of the urban environment that contribute to the convergence of these factors by increasing the concentration of offenders and victims, or reducing guardianship, will result in increased crime rates. Such factors may include characteristics of neighborhoods, such as the age composition of residents or the proportion of rental housing. They may include physical structures in the environment such as bars (Block and Block 1995; Roncek and Maier 1991), schools (Roncek and Faggiani 1985; Roncek and LoBosco 1983), or shopping malls (Engstad 1980) that serve as crime attractors or generators (Brantingham and Brantingham 1991, 1994, 1995; Jarvis 1972).

The primary objective of the current study is to apply these concepts, derived from routine activities theory and previous research on the spatial distribution of crime, to the occurrence of minor property damage throughout one city during a single year. The occurrence of damage incidents as recorded by three different city departments or agencies is considered in relationship to neighborhood characteristics, residential composition, and environmental structures (schools and malls) that contribute to the convergence of likely offenders and reduced guardianship. The research has a number of implications. The link between cumulative property damage and more serious crimes means that the analysis of these crimes can make an important contribution to the understanding of urban crime patterns. Furthermore, because 
property damage and vandalism tend to be directed primarily toward public or impersonal spaces and facilities, an understanding of their etiology may provide a useful model for research into other forms of anonymous environmental damage (Skogan 1990:37). Finally, this research extends the principles of routine activities theory to a previously understudied type of criminal activity, and thus sheds further light on the way in which guardianship and opportunity intersect to permit crimes to occur.

\section{THEORY AND PREVIOUS RESEARCH}

It is well known that crimes tend to cluster in certain areas of a city, so that some areas have higher crime rates than others (Brantingham and Brantingham 1984, 1993; Dunn 1984; Figlio, Hakim, and Rengert 1986; GeorgesAbeyie and Harries 1980). This is one of the least disputed facts about crime, and it has been repeatedly supported by numerous studies spanning several decades, different cities, and diverse offenses. Previous research has examined, for example, the locations of homicides in Cleveland (Bensing and Schroeder 1960), Chicago (Block 1976), and Houston (Bullock 1955); robberies in Seattle (Schmid 1960); and burglaries in Washington, DC (Scarr 1973). Furthermore, it was the early observation of spatial variations that initially contributed to the development of the classical perspectives on crime. Early theorists equated areas of the city with neighborhoods having enduring and distinctive features; this conceptualization led to the development of theories that attempted to explain the criminogenic nature of these areas (Kornhauser 1978). Factors associated with higher crime rates included the proportion of unemployed persons, the amount of rental housing, the overall residential density, and the length of time residents remained in the area. Various mechanisms have been identified that link these area characteristics to the criminal inclinations of residents_-blocked opportunities and the absence of legitimate pursuits, the attraction of illegitimate opportunities, or a general lack of neighborhood social control (Allan and Steffensmeier 1989; Bursik 1988; Park and Burgess 1933; Sampson and Groves 1989; Shaw and McKay 1942; Snodgrass, 1976).

Contemporary research on when and where crimes occur, however, has been strongly influenced by the recognition that human activities, including crimes, take place within a specific social and physical environment (Hawley 1950, 1971). Thus, contemporary studies have taken into consideration the situational context that surrounds the occurrence of criminal events (Sacco and Kennedy 1994), rather than focusing exclusively on offender motivation. Even highly motivated offenders require certain conditions to complete their 
crimes - conditions that include such factors as the vulnerability of victims or targets and the presence or absence of witnesses (Sherman, Gartin, and Buerger 1989). Analyses of situational factors that include the routine activities of both likely offenders and potential victims have demonstrated that these requisite elements of crime converge nonrandomly; that is, some areas provide all the components for crime to occur more frequently and more regularly than others. The circumstances under which crimes occur, from this perspective, are functions of social and structural phenomena that allow people to translate their criminal inclinations into action (Felson 1986, 1994, 1998).

Therefore, the social characteristics of residents of specific areas may not be a direct cause of the crimes rates in those areas (Allan and Steffensmeier 1989). Some, if not all, of the crimes may be committed by outsiders who gravitate to these areas rather than by residents themselves (Costanzo, Halperin, and Gale 1986:74). Crime rates might be high, not because of the criminal inclinations of residents, but because of the criminal opportunities that such areas provide (Dunn 1984; Felson and Cohen 1980). The nature and extent of guardianship in an area is directly related to whether people are at home or away from home and whether there are many people about during different times of day. It is affected by whether residents know their neighbors, and are capable of both recognizing and responding to events that appear out of the ordinary. Social characteristics such as the number of homemakers, single adults, or retired persons living in the area contribute to different patterns of local activity, dictating whether the majority of residents are at home during the day, during the evenings, or only rarely; and whether residents come and go regularly or at all hours.

Residents in their teens or early adulthood are likely to be absent from their homes more frequently, as are those who are single (Felson and Cohen 1980; Hindelang, Gottfredson, and Garofalo 1978). In areas where a large proportion of residents falls into these categories, guardianship may be substantially reduced. Similarly, areas with a high proportion of rental units have a less permanent resident population than well-established owner-occupied housing tracts (Bursik 1988). In areas with a high population turnover, it is less likely that residents will know their neighbors and know who does or does not have a legitimate reason for being in the area. Residents may therefore be unable to exercise informal surveillance by direct observation and by questioning of strangers or suspicious activities (Sampson and Groves1989). Consistent with a routine activities perspective that emphasizes opportunity, higher crime rates in such areas may be directly related to the inability of residents to exercise suitable guardianship. 
The population density of an area, by contrast, may have the opposite effect. Although high density might be hypothesized to increase the convergence of potential offenders and suitable targets, and has been linked by some research to higher crime rates (Hartnagel and Lee 1990), the sheer number of people in an area may make it more difficult for potential offenders to commit a crime without being observed. In general, density may lead to lower rates for crimes that involve secrecy (burglary, for example) and higher rates for crimes that arise from proximity (larceny and muggings) (Decker, Shichor, and O'Brien 1982:52-3; Felson 1998:29; see also Roncek and Faggiani 1985; Roncek and LoBosco 1983; Shlomo 1968).

\section{Physical Structures in the Environment}

In addition to the social environment provided by residents and neighborhoods, the urban landscape is shaped by physical structures that influence human activities. Two types of public structures, shopping malls and high schools, have been identified by previous studies as being significantly related to higher crime rates in adjacent areas (Engstad 1980; Roncek and Faggiani 1985; Roncek and LoBosco 1983). Both serve to attract a large number of nonresidents into an area who come and go with little formal supervision-a situation that not only brings potential offenders into the area, but also reduces guardianship.

Shopping malls. Shopping malls exist for the express purpose of attracting potential customers to the shops and services that they shelter. The large number of people who come and go in the streets around a mall works to reduce effective guardianship, because distinguishing between legitimate patrons and persons who are simply loitering may be difficult. It might be predicted that this combination of factors would result in higher crime rates in the areas immediately adjacent to malls. Consistent with this prediction, Engstad (1980) found significantly higher frequencies of auto crimes, thefts, and miscellaneous offenses in three urban census tracts, each of which contained a major shopping center, ${ }^{1}$ when compared to surrounding areas with similar social and demographic characteristics. Areas with shopping centers had from 2.1 to 6.5 times as many offenses as the averages recorded for adjacent areas, and 1.5 to 3.7 times as many offenses as the maximum recorded for adjacent areas (Engstad 1980:210-11).

High schools. High schools also contribute to increased traffic and activity in the immediate, surrounding vicinity. Furthermore, this population consists 
of persons in their teens, who are implicated in higher rates of offending than other demographic groups. Thus, research into the impact of high schools has consistently demonstrated that their presence is associated with higher crime rates in surrounding neighborhoods. In the first of two studies conducted in medium-sized American cities, Roncek and LoBosco (1983) examined crimes occurring in a relatively new, affluent city that ranked lower in crime rates than other cities of comparable size. The authors report higher rates of several types of index crimes ${ }^{2}$ in one-block areas immediately adjacent to public high schools, ${ }^{3}$ controlling for social, housing, and demographic composition of the areas. Although the size of a school's enrollment was evaluated as a possible predictor, it was found to be nonsignificant.

In a replication of this study using the same variables, Roncek and Faggiani (1985) found similar results in a high-density, high-crime American city. Although the magnitude of effects was different, which reflected the different social, racial, and economic characteristics of the two cities, the presence of a public high school in an area again predicted significantly more crime in the immediately adjacent blocks. Comparable effects were found for public high schools in general, regardless of the size of the school or the type of neighborhood in which it was located (Roncek and Faggiani 1985:502). The geographic distribution of high schools, as the authors observe, is not dependent on neighborhood social characteristics. In other words, high schools are located in both affluent and poor neighborhoods, and in areas with all types of racial and ethnic compositions. The fact that the effect of high schools on crime in surrounding areas remains significant for public high schools in general, controlling for the social features of their environs, is consistent with a routine activities interpretation of varying crime rates.

\section{Routine Activities and Minor Crimes}

Although the impact of routine activities of residents and environmental structures such as schools and malls has been investigated for serious crimes such as robbery, burglary, or rape, these factors have not been considered in relation to minor offenses like property damage. One of the primary justifications for the emphasis on serious crimes, without question, is the potential such offenses have for grave social harm. Such crimes typically and understandably arouse the greatest fear and concern among the public, and they receive the greatest attention and resources from criminal justice agencies. Minor crimes do not appear to pose the same sort of immediate social threat, and hence are usually considered to be of secondary concern. Yet, the rate of occurrence for minor crimes far surpasses, in any city, the rates for more serious offenses. Such crimes as vandalism are a constantly occurring and ever 
present problem in most contemporary North American cities, and their cumulative impact can prove very costly (Bell, Bell, and Godefroy 1988; Skogan 1990). More significant, the accumulation of such incidents has been implicated in the spiral of decay (Felson 1998:131) that leads to the devaluation of urban neighborhoods. The impact is more than economic; the occurrence of minor crimes in an area, especially those that involve visible property damage, may elicit other criminal activity (Chalfant 1992; Challinger 1987; Kelling and Coles 1996).

The assertion that behavior can be formed by the circumstances surrounding it has been criticized as mechanistic at best and environmental determinism at worst (Clarke 1978). It is based, however, on the fundamental tenets of learning theory (Marongiu and Newman 1997; Wortley 1997:66). Specific situational factors can act as eliciting stimuli or behavioral cues to engage in or restrain certain behaviors. For example, in an influential and widely cited study, Zimbardo (1970) demonstrated that "releaser cues," in the form of existing damage, led to the rapid destruction of seemingly abandoned vehicles on the street. The view that criminal events are contingent on the situation in which they occur is consistent with rational theories that attribute actions, including criminal ones, to a balancing of costs and benefits (Clarke and Felson 1993; Cornish and Clarke 1986). Benefits may be perceived as more likely if there is seemingly a low risk of apprehension. Thus, the perception of opportunity may in fact contribute to the occurrence of crime. Risks, on the other hand, particularly the perceived risks of being caught, may work to suppress such behavior. Areas where minor offenses such as property damage or vandalism occur and accumulate may convey a subtle signal to potential offenders that guardianship and social control are low. This perception may be taken, consciously or unconsciously, as an indication that the risks of detection and apprehension for criminal activity are negligible. That perception, in turn, may lead to an escalation in the rate of other, potentially more serious crimes (Felson 1998:131; Wortley 1997:67).

Where and under what circumstances crimes of this nature are most likely to occur may thus make a meaningful contribution to research on urban crime patterns. Similar to crimes that are more serious, minor property damage may result from the convergence of motivated offenders, suitable targets, and the opportunity provided by inadequate guardianship. The role played by these elements, however, can vary considerably, contingent on the nature of the specific criminal act. For some crimes, potential offenders may be highly motivated to seek a suitable target. Other crimes may involve a target that is itself restricted in distribution, so that a crime can only be expected where that target is present. In addition, some crimes require a significant time interval for their completion. For property damage and vandalism, the availability of 
targets is of minimal importance, because targets are structures that are widely available throughout a city. Those who are so inclined can damage almost anything, from the shrubs and trees in parks to the walls and windows of downtown buildings (Christiansen 1983; Geason and Wilson 1990; van Vliet 1992). Furthermore, they may often do so in a very short period of time. The most significant factors contributing to these crimes may therefore simply be the convergence of potential offenders in an area and reduced guardianship.

Social characteristics of areas that contribute to these elements may therefore be associated with higher rates of property damage. Areas that contain many unemployed persons, more young males, more rental than owned housing, and a larger number of transient residents will have greater movement and activity in and around the neighborhood, both during the course of the daily routine and over longer periods of time. These factors, in turn, make it more difficult to distinguish between strangers and residents and to determine the nature of their activities, thereby weakening guardianship. On the other hand, areas of high density and areas where more residents are homemakers or retired, and therefore home for more hours during the day, may not afford anonymous access to unguarded targets. Because potential offenders may feel constrained by the possibility of observation, less damage may occur in such areas.

Beyond the social characteristics of neighborhoods, physical features of the environment, such as malls and schools, that contribute to the convergence of offenders in an area might be expected to result in increased rates of minor crimes, just as with more serious crimes. Malls serve to draw large numbers of people into an area, some of whom may be potential offenders. Malls also impede effective guardianship because of the difficulty in distinguishing between legitimate and illegitimate visitors to the area. The presence of secondary schools within an area can also be expected to result in more crimes of this type because, like malls, such facilities increase local human traffic and thus interfere with guardianship. Furthermore, both malls and schools serve to draw together young people in their teens-the specific age groups most likely to be involved in minor property crime (Beaulieu 1982; Erickson and Jensen 1977; Gladstone 1978; Gold 1970).

\section{THE CURRENT RESEARCH}

In keeping with the foregoing discussion, this study examines the geographic distribution of minor property crime recorded as mischief and vandalism in a medium-sized Canadian city during a 1-year period. ${ }^{4}$ Previous 
studies of the spatial distribution of crime have, for the most part, relied on official crime data as the most widely available and consistent information on crimes throughout all parts of a given geographic area. These statistics usually reflect police activity in response to crime. It is axiomatic that such records undercount crime for a variety of reasons, including the fact that many crimes go unreported and therefore fail to show up in official records. However, underreporting is especially likely to be a problem for official counts of very minor crimes such as property damage and vandalism, because victims may view such incidents as too minor to report. To address the potential methodological issues that arise from reliance on official reports for minor crimes, this study uses three types of data obtained from three departments in the city that served as the study site: the city's Department of Parks and Recreation, its transit department, and its police service. ${ }^{5}$ Using census enumeration areas as a unit of aggregation, ${ }^{6}$ the geographic patterns of these three types of damage are evaluated using ordinary least square (OLS) regression in relationship to two categories of predictors: the social characteristics of residents of each area, taken from municipal census data, and the presence or absence of two types of environmental structures, shopping malls and secondary schools.

\section{METHOD}

Data for this research was collected in Edmonton, Alberta, a western Canadian city with a population of approximately 600,000 . The three agencies cooperating in this research-the police service, the city transit department, and the Department of Parks and Recreation—provided records of the damage done to the facilities under their supervision during the calendar year of 1992. Each of these data sources was unique due to the nature of the targets, the types of incidents that could occur, and the way in which incidents were recorded; thus, merging them into a single composite index was deemed to be unsuitable. Each measure was therefore retained as a separate indicator of damage.

Mischief. Records were obtained from the Edmonton Police Service on all mischief incidents reported during 1992. Under Canadian law, the offence category of mischief refers to willful, malicious damage or public behavior. Most such incidents are property-related vandalism. Because many of them are relatively minor, however, police data are potentially biased, both by underreporting and by differential response. Research indicates that in Canada, as elsewhere, the extent to which citizens report crime varies. For very 
minor offenses, and particularly where there is little likelihood of identifying and arresting an offender, reporting is low (Griffiths and Verdun-Jones 1989; Silverman, Teevan, and Sacco 1996). Canadian victimization surveys reveal that most respondents do not report minor property crimes, even when the property is their own. Typically, less than half of such incidents are reported. Most respondents blame their failure to report on the trivial nature of incidents (60 percent) or on the lack of benefit expected from formal police action (47 percent) (Gartner and Doob 1996). Hence, the majority of incidents involving minor property damage does not show up in official police records. In addition, police responses to citizen complaints may vary according to the seriousness of the crime, considerations of the immediate workload, and time pressures. An officer's perception of the neighborhood where the report comes from may also influence the response (Hagan, Gillis, and Chan 1978). These factors can be expected to substantially restrict the number of incidents of minor property damage that show up in official police records, a reduction that may vary considerably for different neighborhoods.

For this study, additional data were obtained from two other contributing agencies. These data consisted of maintenance records to damaged structures, avoiding the difficulties associated with behavior and selective recording of damage. Where damage was observed, maintenance personnel for each department filed a report indicating their assessment of the cause, whether it was an accident, normal wear and tear, theft, or deliberate damage. In contrast to police data, which provided information on single incidents, both of these agencies kept periodic maintenance records that include an unknown amount of cumulative damage.

Transit vandalism. Records obtained from the transit department reported damage to bus stops and shelters throughout the city. ${ }^{7}$ These records were compiled on the basis of reports from staff maintenance personnel who made regular visits to each shelter. Given the nature of these structures, assessments on the type of damage were deemed to be fairly accurate- their construction is designed to resist most inadvertent damage and discourage theft. The majority of incidents involved damage to the glass or plexiglass panels from which shelters are constructed; graffiti was excluded from the reports. However, maintenance personnel only visited the shelters on their route on a monthly basis. Any damage that was recorded at that time therefore incorporated an unknown number of actual incidents (D. Kowalchuk, personal communication, June 30, 1993).

Park vandalism. Reports on damage to facilities maintained by the Department of Parks and Recreation reflected periodic visits by maintenance 
personnel. Unlike the transit department records, however, which listed only a relatively restricted type of damage to specific types of structures, records from the Department of Parks and Recreation included a wide variety of different incidents, reflecting the greater variation in the types of structures and grounds for which the department had responsibility. In addition to all parks within the municipal limits, the Department of Parks and Recreation maintained recreational facilities, cemeteries, the grounds of public buildings, and tracts of public landscaping. Hence, there were potentially many different types of damage done to lawns, flowerbeds, buildings, pools, and other structures. This greater variety, however, renders the issue of determining the exact nature of damage and judging whether it was deliberate more problematic. Although maintenance personnel attempted to discriminate deliberate damage from accidental, the extent to which these judgments were correct is unknown. In addition, there is no way to ascertain whether similar criteria were used in evaluating incidents in different locations. Decisions were made by individual workers who filed reports on damages and classified them according to the type of incident (W. Gorman, personal communication, June 2, 1993).

\section{Census Enumeration Areas}

Data on population and housing characteristics in the city were obtained from the 1992 City of Edmonton Municipal Census, which reported aggregate information for each census enumeration area. Enumeration areas are subdivisions of the permanent statistical units established by Statistics Canada for the national census (Lalu 1989:1). The smaller enumeration areas do not provide as much demographic detail as the larger census tracts. Their smaller size, however, allows for greater variation in population characteristics. Although the use of such areas has been widespread in the analysis of urban crime patterns (see Brantingham and Brantingham 1984; Felson 1998; Jarvis 1972; Joelsen and Fishbine 1984; Schmid 1960), the technique is associated with a number of shortcomings. Most important of these is that such areas may not correspond, in any meaningful sense, to social or cultural neighborhoods. Some researchers have assumed that there is at least some correspondence between natural neighborhoods and census boundaries (Schmid 1960). Others point out, however, that area perimeters are typically major roads, rivers, and other natural boundaries that are chosen more for their administrative convenience than for demarcating specific neighborhoods (Brantingham and Brantingham 1984:317). As a result, aggregate figures may be purely statistical averages rather than measures of neighborhood homogeneity that distinguish areas from one another. Furthermore, because criminal activity may cluster around major roads and intersections, the use of 
such areas, in effect, may mask significant concentrations of crime by diffusing them among several different adjacent areas.

The routine activities perspective that forms the theoretical basis for this research does not equate the concept of neighborhood with that of community or that of the distinctive sociocultural attributes inherent in this term as developed in the earlier ecological tradition. Nevertheless, some minimal assumption about neighborhood is implicit in the expectation that people can potentially come to know their neighbors, that they may become familiar with their neighbors' children and habitual routines, and that these developments are important in informal guardianship. Although the placement of boundaries along naturally occurring lines of demarcation like main roadways, parks, ravines, and commercial strips may appear to be arbitrary, such divisions also tend to create effective barriers that limit guardianship. Residents preoccupied with daily activities are less likely to take note of events that occur across the park, or across the railroad tracks, than those next door or on their own block. It is in this limited sense that the use of census enumeration boundaries provides a basis for comparing areas.

Area characteristics. Area characteristics that are used as predictors of vandalism and mischief for this research included a measure of residents who had lived 1 year or less at their current address (new residents), calculated as a percentage of the total population in each area. Additional population measures included the percentage of the total population identified as homemakers, as retired, and as unemployed at the time of the enumeration. The two following specific segments of the population were included: males between the ages of 10 and 19 and males between the ages of 20 and 24. Both were calculated as a percentage of the total number of males in the area. ${ }^{8}$ Housing characteristics were calculated as a percentage of the total number of housing units in the area. These included the percentage of renters, rooming houses, and vacant housing units. A final measure, child density, was calculated as the average number of children per household with ages from 5 to $19 .{ }^{9}$

Environmental structures. Malls included in this study were the 17 largest malls in the city. Commercial strips and smaller neighborhood malls were excluded. ${ }^{10}$ Secondary schools included the four following types of schools: the junior and senior high schools of the public school district, and the junior and senior high schools of the Catholic school district. Several schools in the Catholic school district served students at more than one level, including three junior-senior high schools; these schools were coded as high schools in the analysis. Each of these facilities was coded 0 (absence) or 1 (presence). Previous research on the impact of schools (Roncek and Faggiani 1985; 
Roncek and LoBosco 1983) had identified a single-block radius as the extent of significant differences. Therefore, schools were introduced as variables only within the enumeration area in which they were located. The impact of malls, however, was expected to be wider, due in part to their greater use of land within a given area and in part to the greater amount of human traffic that they generate. Therefore, malls were introduced both for their presence within an area and for their presence in an adjacent area. ${ }^{11}$

\section{Mapping of Crime Incidents}

To obtain area measures of crime rates that might be evaluated in relation to area-level predictors, crime data were spatially located within the city using a computerized mapping program (MapInfo) that assigns $x$ and $y$ coordinates to a reference map. ${ }^{12}$ For this study, two base maps were used: a computerized street map containing streets and block numbers for all city addresses, and a map of the boundaries of the census enumeration areas. Mischief incidents as reported by the police department were recorded as specific points, in most cases, a street address, and they were geocoded as such. Of the original 13,537 incidents reported to the police, 97 percent $(13,131)$ were

successfully geocoded. ${ }^{13}$ Locations for the remaining 259 cases ( 1.9 percent) could not be identified. Transit vandalism incidents were recorded as occurring at intersections, with route direction information provided; route direction was used to determine assignment to one of the corners of the intersection. Of the 1,337 incidents, 1,325 were successfully geocoded. Park vandalism incidents were recorded according to the park or facility where they occurred rather than a street address. Each record also indicated a structure or type of structure, such as a pool house or field house; this portion of the record was used to refine the point of location further. Out of the 402 incidents recorded during 1992, all but 9 were successfully geocoded. ${ }^{14}$

All incidents from each source were separately aggregated according to the census enumeration area boundaries, resulting in a total figure for each type of damage within each area. These figures represented the actual count of incidents recorded in each enumeration area. In resident populations, areas ranged from 0 (for six areas of the city) to 3,201 (for the most densely populated). They ranged in size from .027 square kilometers to over 55 square kilometers. These two factors are inversely related; that is, the largest areas were low in population, whereas the smaller areas were high.

Area amounts of crime are generally calculated as a population-based rate, obtained by dividing the total number of crimes by the total population and then multiplying by a constant $(1,000$ or 100,000$)$. Crime rates provide a useful way of comparing units such as cities, states, and even countries, 
because it is plausible to assume that a larger population would contain a larger number of offenders, even if the proportion of such offenders within the population remained constant. For this analysis, however, populationbased rates present a number of shortcomings. Although it is logical to calculate a population-based rate of crime for larger geographical units such as a city in comparison to other cities, because most of the crime in a city can logically be attributed to residents, it is less reasonable to make the same assumption about smaller geographic units such as enumeration areas. Although it may be true that offenders are likely to select targets close to their own residences, the question remains of how close (Costanzo et al. 1986). Five blocks might be considered close; yet, this is a sufficient distance to place a criminal event two enumeration areas away from the offender's home territory. Following a similar argument, Harries asserts that "most if not all the incidents may be attributable to outsiders . . . theoretically, zero events might be 'blamed' on residents, again making nonsense of the rate concept" (Harries 1993:4). This observation is underscored by the fact that crimes can and do occur in areas where there is a very small (or sometimes zero) population. The use of a population-based rate would inflate the amount of crime for these areas. ${ }^{15}$

Difficulties also arise in relation to the physical size of an area. The incidents examined in this research involve crimes, not against individual victims, but against the physical environment. Furthermore, although these crimes are often directed at structures in populated areas such as residences and stores, damage can also occur in parks, ravines, and in industrial or commercial areas. It could therefore be argued that a geographic rate (crimes per square kilometers) would provide a better measure, because larger areas would provide more opportunities for crime. However, the opportunities inherent in available targets, by themselves, are not sufficient to predict crime; it is the convergence of potential offenders with these targets in the absence of suitable guardianship that provides the conditions under which crime is likely to occur. These factors, in turn, are linked to the movements of human activity. Although the empty land around a city's perimeter may theoretically be damaged, areas that are populated, either residentially or because they are activity centers, are likely to experience a greater convergence of all of the components contributing to crime.

These arguments suggest that both the physical size of an area and the number of persons who live there are important considerations; one alone cannot provide an adequate basis for constructing a rate to control for their effects. For this reason, the actual counts of the three types of incidents that occur within each area are retained as measures. To control for the effects of area size and population, these measures are introduced as independent 
variables in the multiple regression analysis (Agresti and Finlay 1997; Bollen and Ward 1980). ${ }^{16}$

\section{Research Limitations}

The three data sets used in this study were divergent in the types of targets that they included and in the way in which damages were assessed. Furthermore, each was vulnerable to differing sources of error in measurement. Although the data obtained from the police reported single acts of mischief involving a variety of targets, they may also have included an unknown number of actions that would not be considered property damage. In addition, the minor nature of offences and the expectation of little satisfaction from a criminal investigation mean that the number of incidents counted would severely underreport the actual occurrence of these crimes. Furthermore, reporting of incidents and police responses could vary by area.

Records obtained from the transit department were subjected less to potential distortion from differential reporting, because they were gathered from actual maintenance records. Uncertainty regarding the nature of the actions involved was also less likely to have been a substantial source of error. Because the targets are stark in construction, providing less variation in the types of potential damage, most of the incidents reported may accurately indicate deliberate damage. These records, however, do not report single incidents. Transit maintenance personnel visited each shelter once a month; therefore, a single record could represent a single act of vandalism or an unknown number of separate acts.

The possibility of cumulative damage is an issue for reports obtained from the parks department as well, because they were also generated from periodic maintenance visits. A given record could reflect a single incident of vandalism or numerous incidents that occurred over a period of time. In addition, these records included various types of damage to many different potential targets. Therefore, there was a greater potential for inaccuracy in the interpreting and reporting of events.

Potential threats to the validity of both transit and park records could arise from differences in use patterns, reflecting how much traffic a particular bus route or park supported, and target availability within specific areas. Some areas in the city may have had many bus shelters; therefore, the total number of incidents reflects only the occasional damage to each of them. Others may have contained only a few shelters that were vandalized many times. Similarly, certain areas of the city contained large tracts of parkland within their boundaries, encompassing a variety of facilities. Other areas, by contrast, had a minimal amount of open grass and are overlooked on all sides by houses. 
These differences could be expected to affect the amount of damage reported in a given area. The data available for this study did not allow any evaluation of these factors; therefore, they represent additional sources of potential bias in the counting of incidents. The difficulties inherent in the measuring and counting of deliberate damage in each of these three data sets are substantial enough that they pose a serious threat to the validity of any one measure taken alone. By their very differences, however, the three types of data lend support to each other (Brantingham and Brantingham 1984). Each was subject to distinctive sources of bias, causing any similarity in their results to underscore their significance. For this reason, patterns revealed by all three measures of damage are emphasized in the regression analysis that follows.

\section{RESULTS}

Edmonton, Alberta had almost three-quarter million residents within its metropolitan limits during 1992, the year for which census data used in this study was gathered. The total area occupied by the city was 690.74 square kilometers (see Table 1). ${ }^{17}$ Schools included 13 senior high schools and 26 junior high schools in the public school district, and 9 senior high schools and 11 junior high schools in the Catholic school district. There were, in addition, 17 shopping malls. The municipal enumeration had identified 662 areas. Listwise elimination of missing cases and the removal of one extreme outlier from the analysis ${ }^{18}$ resulted in 654 areas that were used in the subsequent analysis. The mapping and aggregating of incidents of mischief and vandalism resulted in positively skewed distributions. Extreme scores at the upper end of the distribution for mischief and transit vandalism were recoded at the 90th percentile (Nagin and Smith 1990). ${ }^{19}$ Incidents of recoded mischief ranged from 0 to 37, with a mean of 17.72; recoded transit vandalism ranged from 0 to 5, with a mean of 1.63; and park vandalism ranged from 1 to 29 , with a mean of .59 .

Ordinary least squares (OLS) regression was used to examine relationships between predictors and dependent variables. The results are summarized in Table 2. Of the residential characteristics, the percentage of unemployed $(b=.57, p<.01)$ and the percentage of residents who were males aged 20 to 24 ( $b=.27, p<.01$ ) were found to be statistically significant predictors of increased mischief. Only the percentage unemployed, however, was identified as a statistically significant predictor for all three crime measures. For transit vandalism, it predicted a small increase $(b=.04, p<.05)$, and for park vandalism, a somewhat greater increase $(b=.08, p<.01)$. Other measures of residential characteristics, however, had little consistent impact. Those few 
TABLE 1: Descriptive Statistics: Means, Standard Deviations, Minimums, and Maximums for Variables by Census Enumeration Areas $(N=654)$

\begin{tabular}{|c|c|c|c|c|c|}
\hline Variable & Minimum & Maximum & Total & $\mathrm{M}$ & SD \\
\hline Area per square kilometer & .03 & 55.03 & 690.74 & 1.04 & 4.32 \\
\hline Total population & 0 & 3,201 & 617,299 & 933 & 358 \\
\hline New residents (\%) & .00 & 56.41 & & 20.39 & 11.43 \\
\hline \multicolumn{6}{|l|}{ Resident characteristics (\%) } \\
\hline Homemakers & .00 & 19.62 & & 6.06 & 2.90 \\
\hline Retired & .00 & 98.30 & & 11.76 & 10.12 \\
\hline Unemployed & .00 & 66.67 & & 5.55 & 5.11 \\
\hline Males age 10 to 19 & .00 & 92.05 & & 11.84 & 5.91 \\
\hline Males age 20 to 24 & .00 & 50.82 & & 9.39 & 4.98 \\
\hline \multicolumn{6}{|l|}{ Residences } \\
\hline Total & 0 & 1,246 & 252,325 & 381 & 122 \\
\hline Renters (\%) & .00 & 100.00 & & 44.33 & 28.85 \\
\hline Rooming houses (\%) & .00 & 100.00 & & .40 & 3.94 \\
\hline Vacant (\%) & .00 & 28.68 & & 4.32 & 4.01 \\
\hline Child density & .00 & 9.50 & & .49 & .45 \\
\hline Catholic high school & & & 9 & & \\
\hline Catholic junior high & & & 11 & & \\
\hline Public high school & & & 13 & & \\
\hline Public junior high & & & 26 & & \\
\hline Mall in area & & & 17 & & \\
\hline Mall adjacent & & & 102 & & \\
\hline Mischief incidents ${ }^{a b}$ & .00 & 37.00 & 11,712 & 17.72 & 10.05 \\
\hline Transit vandalism $^{\mathrm{bc}}$ & .00 & 5.00 & 1,079 & 1.63 & 1.91 \\
\hline Park vandalism ${ }^{d}$ & .00 & 29.00 & 394 & .59 & 2.42 \\
\hline
\end{tabular}

SOURCE: City of Edmonton Municipal Census (1992) unless otherwise indicated.

a. Source: City of Edmonton Police Service.

b. Scores above 90th percentile recoded.

c. Source: City of Edmonton Transportation Department.

d. Source: City of Edmonton Parks and Recreation Department.

that were statistically significant for one type of measure proved to be nonsignificant for the other two types. The percentage of new residents was significantly related to mischief $(b=-.13, p<.01)$, but it predicts lower levels instead of the expected higher levels. For transit and park vandalism, the percentage of new residents was nonsignificant. The percentage of area residences that were rooming houses $(b=.22, p<.05)$ and the percentage that were vacant $(b=.41, p<.01)$ were also significant predictors of increased mischief, but not of transit or park damage. The percentage of renters was related to a small but statistically significant increase in both mischief and transit vandalism ( $b=.01, p<.05$ for both), but it was nonsignificant for park vandalism. 
TABLE 2: Regression Coefficients for Mischief Incidents, Transit Damage, and Park Damage on Area Characteristics and Presence of Malls and Schools $(N=654)$

\begin{tabular}{|c|c|c|c|c|c|c|}
\hline \multirow[b]{2}{*}{ Variable } & \multicolumn{2}{|c|}{ Mischief } & \multicolumn{2}{|c|}{ Transit } & \multicolumn{2}{|c|}{ Park } \\
\hline & $\mathrm{b}$ & $\delta$ & $b$ & $\delta$ & $b$ & $\delta$ \\
\hline Area per square kilometer & -.11 & -.05 & -.01 & -.01 & .00 & .00 \\
\hline Total population & $.01^{\star *}$ & .21 & $.00 * *$ & .12 & .00 & -.01 \\
\hline New residents (\%) & $-.13^{\star *}$ & -.15 & -.02 & -.10 & -.01 & -.05 \\
\hline \multicolumn{7}{|l|}{ Resident characteristics (\%) } \\
\hline Homemakers & .24 & .07 & .04 & .08 & -.02 & -.03 \\
\hline Retired & .00 & .05 & .01 & .09 & .01 & .05 \\
\hline Unemployed & $.57^{\star \star}$ & .29 & $.04^{*}$ & .11 & $.08^{\star *}$ & .18 \\
\hline Males age 10 to 19 & .00 & .14 & .01 & .08 & -.01 & -.01 \\
\hline Males age 20 to 24 & $.27^{\star *}$ & .13 & .04 & .01 & -.01 & -.09 \\
\hline \multicolumn{7}{|l|}{ Residences (\%) } \\
\hline Renters & $.01^{*}$ & .15 & $.01^{*}$ & .13 & .01 & .04 \\
\hline Rooming houses & $.22^{*}$ & .09 & .02 & .01 & -.01 & -.01 \\
\hline Vacant & $.41^{\star *}$ & .16 & -.05 & -.01 & -.01 & -.05 \\
\hline Child density & -1.66 & -.08 & -.30 & -.07 & .08 & .01 \\
\hline Catholic high school & 4.13 & .05 & -.98 & -.06 & $2.52^{* \star}$ & .12 \\
\hline Catholic junior high & 2.63 & .03 & .34 & .02 & .29 & .02 \\
\hline Public high school & $8.32^{* *}$ & .11 & $1.15^{*}$ & .08 & $5.35^{\star *}$ & .30 \\
\hline Public junior high & 2.03 & .04 & $.90^{\star}$ & .09 & -.02 & .00 \\
\hline Mall in area & $11.19^{\star *}$ & .18 & $1.61^{* *}$ & .13 & $2.91^{* *}$ & .19 \\
\hline Mall adjacent & $2.58^{\star *}$ & .09 & .21 & .04 & -.37 & -.06 \\
\hline$R^{2}$ & .26 & & .10 & & .21 & \\
\hline
\end{tabular}

${ }^{*} p<.05 .{ }^{* *} p<.01$. Two-tailed tests.

In contrast, the presence or absence of public high schools and shopping malls within an area were consistent and robust predictors for increased damages of all types. Because all these facilities had been coded as dummy variables, the reported coefficients represent the difference between two conditional means-one for those areas with such a structure, and one for those without. The presence of a high school predicted a substantial and statistically significant increase in mischief incidents $(b=8.32)$, transit incidents $(b=$ $1.15)$, and park vandalism $(b=5.35)$. Effects for a mall in a given area were of greater magnitude, with $b=11.19$ for mischief, $b=1.61$ for transit, and $b=$ 2.91 for park vandalism. Contrary to expectations, having a mall in an adjacent area did not predict a significant increase in transit or park vandalism, although the reported effect $(b=2.58)$ was both robust and statistically significant for mischief. Consistent with previous literature, the significant relationship identified for high schools applied only to those of the public school system. Catholic schools were associated with a significant increase in park 
vandalism $(b=2.52, p<.01)$, but they had little consistent relationship to other types of damage. In contrast to the prominent effect identified for high schools, the presence of a junior high school had a negligible impact. Although these schools were statistically significant for predicting transit vandalism, they did not predict a corresponding increase in mischief or park vandalism.

These differences in incidences reported for high schools and malls cannot be attributed to differences in area characteristics, as measured by the variables included in this study. As reported in Table 3, which summarizes comparisons between areas with and without schools and malls, and is based on independent samples $t$ tests, areas containing high schools did not differ significantly from those without in terms of population characteristics. The same conclusion is apparent for areas containing malls, when they are compared to other areas. ${ }^{20}$ These types of structural facilities are dispersed throughout the city in neighborhoods of all kinds. The fact that property crime is consistently higher in surrounding areas appears to be related more to their presence than to any distinctive differences in the residential environment.

\section{DISCUSSION}

Damage or vandalism was defined, measured, and counted in widely divergent ways by the agencies that provided data for this research. These three measures of damage, however, yielded very similar results when their spatial patterns throughout the city were examined. In spite of the expectation that residential and neighborhood characteristics would influence the amount of property crime that occurred in an area, these variables had little consistent impact for all types of damage. The unemployment rate, however, was a significant predictor of increased levels of mischief and transit and park vandalism. Other characteristics that were expected to increase the likelihood of property damage were either nonsignificant (the percentage of teen males living in an area) or were predictors of one type of damage but not another (the percentage of local housing that was renter occupied). Those areas with high schools and malls, however, were found to have consistently higher rates of all three types of damage, controlling for differences in social, residential, and demographic characteristics. These results are consistent with a routine activities interpretation of the circumstances in which damage occurs. Routine activities theory argues that crimes will be committed when potential offenders are confronted with the opportunities afforded by available targets in situations of reduced guardianship. Based on that model, the 
TABLE 3: Comparison of Means for Areas with and without Schools and Malls: Independent Samples $t$ Tests $(N=654)$

\begin{tabular}{|c|c|c|c|c|c|c|c|c|c|}
\hline \multirow[b]{2}{*}{ Structure } & \multirow[b]{2}{*}{$\mathrm{n}$} & \multicolumn{5}{|c|}{ Resident Characteristics (in percentages) } & \multicolumn{3}{|c|}{ Damage Incidents } \\
\hline & & $\begin{array}{c}\text { New } \\
\text { Residents }\end{array}$ & Unemployed & $\begin{array}{c}\text { Males Age } \\
10 \text { to } 19\end{array}$ & $\begin{array}{c}\text { Males Age } \\
20 \text { to } 24\end{array}$ & Renters & Mischief & Transit & Park \\
\hline \multicolumn{10}{|c|}{ Catholic school } \\
\hline \multicolumn{10}{|c|}{ High school } \\
\hline Present & 9 & 18.07 & 4.68 & 11.52 & 6.94 & 39.40 & 23.22 & 1.00 & 3.44 \\
\hline Absent & 645 & 20.45 & 5.57 & 11.86 & $9.41^{*}$ & 44.39 & 17.67 & 1.64 & .56 \\
\hline \multicolumn{10}{|l|}{ Junior high } \\
\hline Present & 11 & 17.20 & 6.91 & 11.73 & 7.93 & 37.01 & 21.73 & 2.72 & 1.09 \\
\hline Absent & 643 & 20.48 & 5.54 & 11.86 & $9.40^{*}$ & 44.45 & 17.67 & 1.62 & .59 \\
\hline \multicolumn{10}{|l|}{ Public school } \\
\hline \multicolumn{10}{|l|}{ High school } \\
\hline Present & 12 & 20.32 & 4.78 & 9.97 & 6.67 & 54.78 & 29.16 & 3.33 & 6.75 \\
\hline Absent & 642 & 20.42 & 5.57 & 11.98 & 9.39 & 44.13 & $17.52^{* *}$ & $1.61^{*}$ & .48 \\
\hline \multicolumn{10}{|l|}{ Junior high } \\
\hline Present & 26 & 14.39 & 4.08 & 11.97 & 7.83 & 37.49 & 19.88 & 2.80 & .84 \\
\hline Absent & 628 & $20.67^{* *}$ & $5.62^{* *}$ & 11.85 & $9.44^{* *}$ & 44.61 & 17.65 & $1.59^{\star *}$ & .59 \\
\hline \multicolumn{10}{|l|}{ Mall } \\
\hline \multicolumn{10}{|l|}{ In area } \\
\hline Present & 17 & 24.44 & 6.55 & 10.18 & 9.84 & 59.86 & 31.11 & 3.59 & 4.41 \\
\hline Absent & 637 & 20.31 & 5.53 & 11.90 & 9.37 & 43.91 & $17.38^{\star *}$ & $1.59^{\star *}$ & $.50^{* *}$ \\
\hline \multicolumn{10}{|l|}{ Adjacent } \\
\hline Present & 102 & 21.37 & 6.32 & 11.92 & 9.69 & 50.01 & 21.76 & 2.00 & .59 \\
\hline Absent & 552 & 20.24 & 5.42 & 11.84 & 9.32 & $43.28^{*}$ & $17.00^{* *}$ & $1.57^{\star}$ & .60 \\
\hline
\end{tabular}

${ }^{*} p<.05 .{ }^{* *} p<.01$. Two-tailed tests. 
observation that mischief and vandalism are concentrated in certain locations can be interpreted as reflecting differences in the way those areas and their surroundings permit the convergence of these factors. High schools are built throughout the populated areas of a city, in prosperous neighborhoods as well as poorer ones. Similarly, shopping malls are scattered throughout the urban landscape. Both schools and malls are public structures that generate a steady flow of traffic into and out of an area, and draw in a high volume of nonresidents. The increased traffic that results not only contributes to the convergence of potential offenders, it also impedes guardianship by making it more difficult to distinguish loiterers with an illegitimate purpose from those with a legitimate one. Thus, it might be argued that these structures provide situational incentives to commit crime.

The way in which unemployment affects the amount of property damage occurring in some areas, however, is open to several alternative interpretations. Areas with high unemployment are typically the poorer areas of a city (Kornhauser 1978) ${ }^{21}$ Are residents of these areas more inclined to damage and destroy their surroundings than residents in better neighborhoods? It might be, as some writers have argued, that the urban poor lack social ties and experience marginalization; therefore, they destroy the symbols of a society that has largely excluded them. The physical damage inflicted on their surroundings, according to this interpretation, represents a form of "nonverbal communication ... the mutilation of objects and environments for which the perpetrator does not feel any code fellowship" (Roos 1992:75, 81; see also Cohen 1973).

This explanation is consistent with classic structural theories that have their roots in the concept of social disorganization. By implication, higher crime rates in these areas are attributed to the activities of local residents. Although the argument may be a valid one, its accuracy cannot be determined based on aggregate data (Robinson 1950). Furthermore, the link between unemployment and property crime could occur due to factors unrelated to the motivation or inclinations of area residents. Areas with high unemployment tend to be, as previously noted, poorer areas of the city, and these areas often contain a housing mix characterized by multifamily dwellings, low-rise apartment buildings, and row housing. Areas where these multiple-family housing facilities dominate may be deficient in structurally imposed forms of guardianship (Crowe 1991; Crowe and Zahm 1994; Hough and Mayhew 1980; Wilson 1978). These facilities often include common areas in parking lots, pathways, and open spaces between buildings. Public areas of this type render informal surveillance and supervision more difficult, and the lack of ownership implicit in such land use may discourage residents from intervening in questionable activities (Felson 1998; Geason and Wilson 1990; see 
also Newman 1972). Furthermore, the routine daily activities of residents are frequently less predictable in areas of high unemployment. Lacking the imposed constraints of a daily work schedule, unemployed persons are more likely to enter and depart their premises according to idiosyncratic circumstances rather than according to a repetitive and habitual routine. Residents of these areas are thus less likely to be able to assess the legitimacy or illegitimacy of neighborhood traffic, and they may therefore fail to challenge activities or persons about whom they are uncertain. Hence, some or all of the effects identified for unemployment as a predictor of increased property crime may be related to the reduced guardianship in these areas rather than differences in motivation.

Routine activities theory, and the notion that crimes occur in certain places because of the criminal opportunities provided by the physical environment of those places, provides an explanation for the patterns of minor property crime analyzed in this research. However, there is still the question of whether the opportunities presented by circumstances in certain areas prompt the motivation to act, or whether the crimes that occur there would have occurred anyway (Sherman et al. 1989). This issue is relevant to this study of property crime, but it is also germane to the question of whether the occurrence of such crimes creates an atmosphere of low guardianship, which then leads to more serious crimes. If crimes occur in certain locations because motivated offenders actively seek out opportunities to wreak their damage, then identifying criminogenic areas or hot spots and the circumstances that generate them is simply an effort in description. Furthermore, increasing guardianship in such locations will accomplish little other than displacement.

Felson and Cohen argue that motivations may remain static, whereas opportunities to commit crime fluctuate according to variations in patterns of routine human activities (1980:397). Similarly, Gottfredson and Hirschi (1990) have suggested that offenders have an inherent, unvarying criminality; the occurrence of specific crimes, however, is shaped largely by immediate opportunities. These explanations of offending portray human behavior as the product of the weighing of risks versus benefits, and they are analogous to more traditional versions of control theory, which assert that deviant behavior is an omnipresent vulnerability (Hirschi 1969; Kornhauser 1978:24). Such models of offending suggest that opportunities implicit in reduced guardianship might do more than simply provide the context for events that would inevitably have happened somewhere. Instead, such opportunities might act to stimulate the behavior, and thus act as proximate causes. 


\section{CONCLUSION}

This research extends the geographic analysis of crime patterns, which has previously focused on serious index crimes, to study the occurrence of minor property crimes in a Canadian city during a 1-year period. As with the index crimes examined in previous research, the results of this study reveal a marked concentration of criminal incidents in certain areas-specifically, those containing high schools or malls, and those with higher unemployment. Reasons for the concentration of mischief and vandalism in these areas have been framed in terms of routine activities theory's model of crime as arising from the convergence of offenders and targets in the absence of effective guardianship. The results support the conclusion that situational opportunities presented by urban ecological features can account for variations in crime patterns. Some urban areas, due to their residential composition, may be particularly attractive to vandals and to those inclined to minor property crime because they afford inherently low guardianship. Further weakening of guardianship is brought about by the presence of facilities like schools and malls that bring a large number of nonresidents into the vicinity on a daily basis. Furthermore, these facilities attract the segments of population most likely to engage in minor damage and vandalism-people in their teens. Although replication is necessary to confirm these findings, the results of this analysis have implications for crime control. If minor property damage and vandalism are seen as the product of routine activities that arise primarily from the convergence of offenders and reduced guardianship, then prevention may most effectively be focused on disrupting the way in which these factors intersect-through an increase in both active and passive guardianship. Furthermore, the relevance of these findings goes beyond the damage itself. Crimes such as vandalism and mischief are often trivial as single events, but they are collectively significant in their impact on the perception of guardianship, and hence on potential offenders' weighing of the risks and benefits associated with more serious and socially harmful criminal behavior. The accumulation of property crime in an area may provide a signal to the criminally inclined that there is little likelihood of apprehension; therefore, such areas become likely sites for more serious criminal activities. In light of recent research into what has been described as the broken windows effect, an understanding of the circumstances surrounding minor property damage sheds further light on urban crime patterns more generally. 


\section{NOTES}

1. The cited research uses the term shopping center to describe the retail facilities studied, in contrast to the current usage of the term mall. Although there is a semantic distinction between the two terms based on whether facilities have a common nonretail area (the mall itself), the city in which the current research was conducted does not make such a distinction. The two terms are therefore used interchangeably in this study.

2. The offence categories examined were murder, rape, assault, robbery, burglary, grand theft, and auto theft (Roncek and LoBosco 1983).

3. A similar effect was not observed for private high schools. The authors speculated that "the grounds of public high schools are public property and legitimately available for use by anyone while the grounds of private schools are not" (Roncek and LoBosco 1983).

4. Vandalism is defined variously as "intentional acts aimed at damaging or destroying" (Moser 1992); "intentional hostile behavior aimed at damaging environmental objects"; "wilful or malicious destruction, injury, disfigurement, or defacement" (Federal Bureau of Investigation 1994; see also Cohen 1973; Levy-Leboyer 1984). Although the term vandalism is commonly used in Canada, it is not contained in the Canadian Criminal Code. Instead, instances of vandalism are recorded and prosecuted under the statutes for mischief.

5. Incidents involving property damage and vandalism are recorded under the Canadian Criminal Code as mischief more than or less than \$1,000 (Rodriques 1990:210-211, section 430). Although offences recorded under this section usually refer to property damage, some incidents may refer to other behavior. Section 430.1 of the Canadian Criminal Code states that "Everyone commits mischief who willfully (a) destroys or damages property; (b) renders property dangerous, useless, inoperative or ineffective; (c) obstructs, interrupts or interferes with the lawful use, enjoyment or operation of property" (Rodriques 1990:210-211). Section 430.1.1 adds that anyone who "destroys or alters data," "renders data meaningless, useless, or ineffective," or otherwise interferes with data is also guilty of mischief (Rodriques 1990:210-211). Actions falling within the latter subsection would not be considered property damage. It is, however, impossible to determine from the data source whether police records on mischief include offenses of this nature, and, if so, how many.

6. Enumeration areas are subdivisions of the permanent census tracts established by Statistics Canada, and they represent the smallest unit of census aggregation. There are typically several enumeration areas within a tract. Their boundaries are intended to define an area as homogenous as possible in terms of socioeconomic characteristics and to follow, where feasible, well-established natural boundaries (Lalu 1989:1).

7. Although the transit department maintained additional records on damage to buses and Light Rail Transit trains, they were excluded from this study, because they could not be spatially located.

8. Age groupings were chosen to allow a measure of residents in their teens or early adulthood. Actual cutoffs between age groups, however, reflect the limitations of the municipal census data, which recorded age by gender in categories rather than in any substantive or legal distinctions (in Canada, the cutoff between juvenile and adult status is 18 years).

9. Child density was include instead of broader measures of residential or neighborhood density; this was based on previous research that has identified this measure as predictive of increased levels of minor property damage (see Wilson 1978).

10. Commercial strips and smaller neighborhood malls were excluded because an exhaustive, valid measure of their presence or absence in a given area could not be developed for the city in which data were gathered. Many areas contained small, neighborhood strip malls that were identifiable as separate corporate entities. Others had commercial strips of very similar 
composition (typically centering on fast food outlets or convenience stores) that reflected the clustering of separate facilities within a municipal commercial zone. These latter areas were not identified as malls, although they effectively functioned as such.

11. An adjacent area was operationally defined as one sharing one or more common boundaries with an area containing a mall.

12. More detailed information on the technique of geocoding used for this study is available from the author.

13. This number includes three types of records: (1) those which had been recorded as a specific street address; (2) those recorded as occurring at a particular named building or facility, which in turn had a street address; and (3) those recorded as occurring at an intersection. For the latter group of incidents, a specific street address could not be identified, nor could it be determined on which of four potential corners an incident had occurred. All incidents of this nature were therefore geocoded to the northwest corner of the intersection.

14. Missing data for the three types of property damage incidents included cases in which an address or specific location could not be identified, cases in which the indicated address or location did not exist (recording agency errors), and cases in which the indicated address or location corresponded to two or more potential locations.

15. The use of a population figure as the denominator in calculating a rate for the dependent variable may lead to spurious positive results if the same population figure is used to compute independent variables. Such a situation might arise in this analysis because predictors include the percentage of area residents falling into certain demographic categories (Bollen and Ward 1980: 61).

16. A further source of potential bias arises from the nature of the data and the possibility of spatial autocorrelation. Multivariate analyses such as the ordinary least squares (OLS) regression models employed in this study are based on the expectation that error terms are independent and do not vary systematically - a requirement that is rarely met with spatial data (Upton and Fingleton 1985:371). Instead, such data are likely to exhibit organized patterns or systematic spatial variation in values across a map (Cliff and Ord 1981:6; Upton and Fingleton 1985:151). High unemployment rates in one area, for example, do not abruptly drop at the border of that area, they tend to continue into neighboring areas. Such facilities as shopping malls, by contrast, will almost universally be absent from any area next to one in which they are present. However, the impact of such potential sources of bias is reduced as $n$ increases (Upton and Fingleton 1985:365), and this study employs a fairly large $n$ of over 650. Although spatial statistics have been developed to correct for such problems (see Anselin 1990a, 1990b; Anselin et al. 1996; Blommestein and Koper 1997), they involve more complex models than OLS regression and thus are appropriate if it appears that autocorrelation contributes to a significant distortion of coefficients. For this analysis, a post-hoc analysis of the differences between theoretically derived (expected) values and the corresponding observed values suggested little consistent spatial patterning that would seriously bias results, and hence regression models were retained (Cliff and Ord 1981:76).

17. The dimensions are those calculated by summing the area per square kilometer for all enumeration areas defined by the City of Edmonton Municipal Census (1992) using mapping software. The size varies somewhat from that reported by other sources.

18. A single enumeration area was excluded from the analysis as an outlier. There were no statistically significant differences in population characteristics when this area was compared to others in the city. All measures were within one standard deviation of the mean for the city as a whole. It differed, however, in that it contains an architectural phenomenon touted as "the world's largest shopping mall." Although the relative size of malls was not included as a variable in this study, the enormity of this structure places it in a category by itself, so that it could not be 
treated as equivalent to other malls. It should be noted, however, that mischief and vandalism rates recorded for this area were extremely high, consistent with the assumption that such a facility would predict increased amounts of crime.

19. Recoding of park vandalism would have restricted this measure to three categories, which was deemed to provide inadequate variation. This measure was thus retained as recorded in the data.

20. The only exception is size; areas containing malls and schools are significantly smaller than those without. This finding is consistent with the observation, made previously, that there was an inverse relationship between area size and population. Larger areas were the more sparsely populated outlying districts, reflecting their smaller number of residents; they were less likely to contain schools and malls. Densely populated areas closer to the midzones of the city, by contrast, were smaller, but they were more likely to contain such facilities.

21. The data used to analyze residential characteristics in this study did not contain measures of average income or median housing values, which would have permitted a more direct measure of socioeconomic status.

\section{REFERENCES}

Agresti, A., and B. Finlay. 1997. Statistical Methods for the Social Sciences. 3d ed. Saddle River, NJ: Prentice-Hall.

Allan, E. A., and D. J. Steffensmeier. 1989. "Youth, Underemployment, and Property Crime: Differential Effects of Job Availability and Job Quality on Juvenile and Young Adult Arrest Rates." American Sociological Review 54:107-123.

Anselin, Luc. 1990a. "Some Robust Approaches to Testing and Estimation in Spatial Econometrics." Regional Science and Urban Economics 29:141-63.

—. 1990b. "Spatial Dependence and Spatial Structural Instability in Applied Regression Analysis." Journal of Regional Science 30:185-207.

Anselin, Luc, Anil K. Bera, Raymond Florax, and Mann J. Yoon. 1996. "Simple Diagnostic Tests for Spatial Dependence.” Regional Science and Urban Economics 26:77-104.

Beaulieu, L. 1982. Vandalism: Responses and Responsibilities. Report of the Task Force on Vandalism. Ontario, Canada: Queen's Printer.

Bell, M. M., M. M. Bell, and K. Godefroy. 1988. "The Impact of Graffiti on Neighborhoods and One Community's Response." Presented at the International Symposium on Vandalism: Research, Prevention, and Social Policy, April 20-23, Seattle, WA.

Bensing, R. C., and O. Schroeder, Jr. 1960. Homicide in an Urban Community. Springfield, IL: Charles Thomas.

Block, R. 1976. "Homicide in Chicago: A Nine-Year Study (1965-1973).” Journal of Criminal Law and Criminology 66:510.

Block, R. L., and C. R. Block. 1995. "Space, Place, and Crime: Hot Spot Areas and Hot Places of Liquor-related Crime." Pp. 145-83 in Crime Prevention Studies, vol 4, Crime and Place, edited by J. E. Eck and D. Weisburd. Monsey, NY: Criminal Justice Press.

Blommestein, Hans J., and Nick A. M. Koper. 1997. "The Influence of Sample Size on the Degree of Redundancy in Spatial Lag Operators." Journal of Econometrics 82:317-33.

Bollen, K. A., and S. Ward. 1980. "Ratio Variables in Aggregate Data Analysis." Pp. 60-79 in Aggregate Data: Analysis and Interpretation, edited by E. F. Borgatta and D. J. Jackson. Beverly Hills, CA: Sage.

Brantingham, P. J., and P. L. Brantingham. 1991. Environmental Criminology. Prospect Heights, IL: Waveland. 
1994. "Mobility, Notoriety, and Crime: a Study in Crime Patterns of Urban Nodal Points.” Journal of Environmental Systems 11:89-99.

Brantingham, P. L., and P. J. Brantingham. 1984. Patterns in Crime. New York: Macmillan.

. 1993. "Environment, Routine and Situation: Toward a Pattern Theory of Crime." Pp. 259-94 in Routine Activity and Rational Choice: Advances in Criminological Theory, edited by R. V. Clarke and M. Felson. New Brunswick, NJ: Transaction Books.

1995. "Criminality of Place: Crime Generators and Crime Attractors.” European Journal of Criminal Policy and Research 3:5-26.

Bullock, H. A. 1955. "Urban Homicide in Theory and Fact.” Journal of Criminal Law, Criminology, and Police Science 45:565-75.

Bursik, R. J., Jr. 1988. "Social Disorganization and Theories of Crime and Delinquency: Problems and Prospects." Criminology 26:519-51.

Chalfant, H. 1992. "No One Is in Control." Pp. 4-11 in Vandalism: Research, Prevention and Social Policy, edited by H. H. Chistensen, D. R. Johnson, and M. H. Brookes. Portland, OR: Department of Agriculture Forest Service.

Challinger, D. 1987. Preventing Property Crime: Proceedings of a Seminar. Canberra: Australian Institute of Criminology.

Christiansen, M. L. 1983. Vandalism Control Management for Parks and Recreational Areas. University Park, PA: Venture Publishing.

City of Edmonton Municipal Census. 1992. Census Summary Data File. Edmonton, Canada: City of Edmonton Computing Resources.

Clarke, R.V.G. 1978. Tackling Vandalism. Home Office Research Study No. 47. London, UK: HMSO.

Clarke, R.V.G., and M. Felson. 1993. Routine Activity and Rational Choice. New Brunswick, NJ: Transaction Press.

Cliff, Andrew D., and J. K. Ord. 1981. Spatial Process: Models and Applications. London, UK: Pion.

Cohen, L. E., and M. Felson. 1979. "Social Change and Crime Rate Trends: A Routine Activity Approach.” American Sociological Review 44:588-608.

Cohen, S. 1973. "Property Destruction: Motives and Meanings." Pp. 23-54 in Vandalism, edited by Colin Ward. New York: Van Nostrand Reinhold.

Cornish, D. B., and R. V. Clarke. 1986. The Reasoning Criminal: Rational Choice Perspectives on Offending. New York: Springer-Verlag.

Costanzo, C. M., W. C. Halperin, and N. Gale. 1986. "Criminal Mobility and the Directional Component in Journeys to Crime.” Pp. 73-95 in Metropolitan Crime Patterns, edited by R. M. Figlio, S. Hakim, and G. F. Rengert. Monsey, NY: Willow Tree Press.

Crowe, T. D. 1991. Crime Prevention Through Environmental Design: Applications of Architectural Design and Space Management Concepts. Boston, MA: Butterworth-Heinemann.

Crowe, T. D., and D. Zahm. 1994. "Crime Prevention Through Environmental Design.” Land Management 7:220-27.

Decker, David L., David Shichor, and Robert M. O'Brien. 1982. Urban Structure and Victimization. Lexington, MA: Lexington Books/D. C. Heath and Company.

Dunn, C. S. 1984. "Crime Area Research.” Pp. 5-25 in Patterns in Crime, edited by P. L. Brantingham and P. J. Brantingham. New York: Macmillan.

Engstad, P. A. 1980. "Environmental Opportunities and the Ecology of Crime.” Pp. 206-22 in Crime in Canadian Society (2d ed.), edited by R. A. Silverman and J. J. Teevan, Jr. Toronto, Canada: Butterworths. 
Erickson, M. L., and G. F. Jensen. 1977. "Delinquency Is Still Group Behavior!: Toward Revitalizing the Group Premise in the Sociology of Deviance." Journal of Criminal Law and Criminology. 68:262-73.

Federal Bureau of Investigation. 1994. Uniform Crime Reports. Washington, DC: Government Printing Office.

Felson, M. 1986. "Routine Activities, Social Controls, Rational Decisions and Criminal Outcomes.” Pp. 119-28 in The Reasoning Criminal, edited by D. Cornish and R. V. Clarke. New York: Springer-Verlag.

_. 1987. "Routine Activities and Crime Prevention in the Developing Metropolis." Criminology 25:911-31.

- 1994. Crime and Everyday Life. Thousand Oaks, CA: Pine Forge Press. - 1998. Crime \& Everyday Life. 2d ed. Thousand Oaks, CA: Pine Forge Press.

Felson, M., and L. E. Cohen. 1980. "Human Ecology and Crime: A Routine Activity Approach." Human Ecology 8:389-406.

Figlio, R. M., S. Hakim, and G. F. Rengert. 1986. Metropolitan Crime Patterns. Monsey, NY: Willow Tree Press.

Gartner, R., and A. N. Doob. 1996. “Trends in Criminal Victimization: 1988-1993.” Pp. 90-104 in Crime in Canadian Society ( $5 \mathrm{~d}$ ed.), edited by R. A. Silverman, J. J. Teevan Jr., and V. F. Sacco. Toronto, Canada: Butterworths.

Geason, S., and P. R. Wilson. 1990. Preventing Graffiti and Vandalism. Canberra: Australian Institute of Criminology.

Georges-Abeyie, D. E., and K. D. Harries. 1980. Crime: A Spatial Perspective. New York: Columbia University Press.

Gladstone, F. J. 1978. "Vandalism Amongst Adolescent Schoolboys.” Pp. 19-39 in Tackling Vandalism, Home Office Research Study No. 47, edited by R. V. G. Clarke. London, UK: HMSO.

Gold, M. 1970. Delinquent Behavior in an American City. Belmont, CA: Brooks-Cole.

Gottfredson, M. R., and T. Hirschi. 1990. A General Theory of Crime. Stanford, CA: Stanford University Press.

Griffiths, C. T., and S. N. Verdun-Jones. 1989. Canadian Criminal Justice. Toronto, Canada: Butterworths.

Hagan, John, A. R. Gillis, and J. Chan. 1978. "Explaining Official Delinquency: A Spatial Study of Class Conflict and Control.” Sociological Quarterly 19:386-98.

Harries, K. 1993. "The Ecology of Homicide and Assault: Baltimore City and County, 1989-1991." Presented at the American Society of Criminology Annual Meetings, November 4, Phoenix, AZ.

Hartnagel, T. F., and G. Won Lee. 1990, October. "Urban Crime in Canada." Canadian Journal of Criminology :591-606.

Hawley, A. H. 1950. Human Ecology: A Theory of Community Structure. New York: Ronald Press.

-1971. Urban Society: An Ecological Approach. New York: Ronald Press.

Hindelang, M. J., M. R. Gottfredson, and J. Garofalo. 1978. Victims of Personal Crime: An Empirical Foundation for a Theory of Personal Victimization. Cambridge, MA: Ballinger.

Hirschi, T. 1969. Causes of Delinquency. Berkeley: University of California Press.

Hough, M., and P. Mayhew. 1980. Crime and Public Housing: Proceedings of a Workshop. London, UK: Home Office.

Jarvis, G. K. 1972. "The Ecological Analysis of Juvenile Delinquency in a Canadian City." Pp. 195-211 in Deviant Behavior and Society Reaction, edited by C. L. Boydell, C. F. Grindstaff, and P. C. Whitehead. Toronto, Canada: Holt, Rinehart and Winston. 
Joelson, M. R., and G. M. Fishbine. 1984. "The Display of Geographic Information in Crime Analysis." Pp. 249-63 in Patterns in Crime, edited by P. L. Brantingham and P. J. Brantingham. New York: Macmillan.

Kelling, G. L., and C. Coles. 1996. Fixing Broken Windows: Restoring Order and Reducing Crime in Our Communities. New York: Free Press.

Kornhauser, R. R. 1978. Social Sources of Delinquency. Chicago, IL: University of Chicago Press.

Lalu, N. M. 1989. Changing Profiles of Edmonton Census Tracts. Edmonton, Canada: University of Alberta Population Research Laboratory.

Levy-Leboyer, C. 1984. Vandalism: Behavior and Motivations. New York: North-Holland.

Marongiu, P., and G. Newman. 1997. "Situational Crime Prevention and the Utilitarian Tradition." Pp. 115-35 in Rational Choice and Situational Crime Prevention: Theoretical Foundations, edited by G. Newman, R. V. Clarke, and S. G. Shoham. Dartmouth, VT: Ashgate Publications.

Moser, G. 1992. "What Is Vandalism? Towards a Psycho-social Definition and its Implications." Pp. 49-70 in Vandalism: Research, Prevention, and Social Policy, edited by H. H. Chistensen, D. R. Johnson, and M. H. Brookes. Portland, OR: Department of Agriculture Forest Service.

Nagin, D. S., and D. A. Smith. 1990. "Participation in and Frequency of Delinquent Behavior: A Test for Structural Differences." Quantitative Criminology 6:335-65.

Newman, O. 1972. Defensible Space: Crime Prevention Through Urban Design. New York: Macmillan.

Park, R. E., and E. W. Burgess. 1933. Introduction to the Science of Sociology. 2d ed. Chicago, IL: University of Chicago Press.

Robinson, W. S. 1950. "Ecological Correlation and the Behavior of Individuals." American Sociological Review 15:351-7.

Rodriques, Gary P., ed. 1990. Canadian Criminal Code. Pocket Criminal Code. Toronto, Canada: Carswell.

Roncek, D. W., and D. Faggiani. 1985. "High Schools and Crime: a Replication.” The Sociological Quarterly 26:491-505.

Roncek, D. W., and A. LoBosco. 1983. "The Effect of High Schools on Crime in Their Neighborhoods.” Social Science Quarterly 64:598-613.

Roncek, D. W., and P. Maier. 1991. "Bars, Blocks, and Crimes Revisited: Linking the Theory of Routine Activities to the Empiricism of Hot Spots." Criminology 29:725-53.

Roos, H. 1992. "Vandalism as a Symbolic Act in 'Free-zones." Pp. 71-87 in Vandalism: Research, Prevention, and Social Policy, edited by H. H. Christensen, D. R. Johnson, and M. H. Brookes. Portland, OR: Department of Agriculture Forest Service.

Sacco, V. F., and L. W. Kennedy. 1994. The Criminal Event. Scarborough, Canada: Nelson.

Sampson, R. J., and W. B. Groves. 1989. "Community Structure and Crime: Testing Social Disorganization Theory.” American Journal of Sociology 94:774-802.

Scarr, H. A. 1973. Patterns of Burlgary. Washington, DC: Law Enforcement Assistance Administration, National Institute of Law Enforcement and Criminal Justice.

Schmid, C. F. 1960. "Urban Crime Areas, Part I \& Part II." American Sociological Review 25:527-43, 655-78.

Shaw, C. R., and H. D. McKay. 1942. Juvenile Delinquency and Urban Areas. Chicago, IL: University of Chicago Press.

Sherman, L. W., P. R. Gartin, and M. E. Buerger. 1989. "Hot Spots of Predatory Crime: Routine Activities and the Criminology of Place." Criminology 17:17-49. 
Shlomo, Angel. 1968. "Discouraging Crime Through City Planning." Working Paper No. 75, Space Sciences Laboratory and the Institute of Urban and Regional Development, University of California, Berkeley, CA.

Silverman, R. A., J. J. Teevan, Jr., and V. F. Sacco. 1996. Crime in Canadian Society. 5d ed. Toronto, Canada: Harcourt Brace.

Skogan, W. G. 1990. Disorder and Decline: Crime and the Spiral of Decay in American Neighborhoods. New York: Free Press.

Snodgrass, J. 1976. “C. R. Shaw and H. D. Mckay: Chicago Criminologists.” The British Journal of Criminology 16:1-19.

Upton, Graham J. G., and Bernard Fingleton. 1985. Spatial Data Analysis by Example. New York: Wiley.

van Vliet, W. 1992. "The Cherry Question or the Role of Social Science Research in Designing Against Vandalism.” Pp. 31-48 in Vandalism: Research, Prevention, and Social Policy, edited by H. H. Chistensen, D. R. Johnson, and M. H. Brookes. Portland, OR: Department of Agriculture Forest Service.

Wilson, S. 1978. "Vandalism and 'Defensible Space' on London Housing Estates.” Pp. 41-65 in Tackling Vandalism. Home Office Research Study No. 47, edited by R. V. G. Clarke. London, UK: HMSO.

Wortley, R. 1997. "Reconsidering the Role of Opportunity in Situational Crime Prevention." Pp. 65-81 in Rational Choice and Situational Crime Prevention: Theoretical Foundations, edited by G. Newman, R. V. Clarke, and S. G. Shoham. Dartmouth, VT: Ashgate Publications.

Zimbardo, Philip. 1970. "The Human Choice: Individuation, Reason, and Order Versus Deindividuation, Impulse, and Chaos.” Pp. 237-307 in Nebraska Symposium on Motivation, edited by W. Arnold and D. Levine. Lincoln: University of Nebraska Press. 